\title{
Comparison of Shade of Ceramic with Three Different Zirconia Substructures using Spectrophotometer
}

\author{
${ }^{1}$ Syed Rashid Habib, ${ }^{2}$ Ibraheem F Al Shiddi
}

\begin{abstract}
Objective: This study assessed how changing the Zirconia $(\mathrm{Zr})$ substructure affected the color samples after they have been overlaid by the same shade of veneering ceramic.
\end{abstract}

Materials and methods: Three commercial Zr materials were tested in this study: Prettau ${ }^{\circledR}$ Zirconia (ZirKonZahn, Italy), Cercon (Dentsply, Germany) and InCoris ZI (Sirona, Germany). For each system, 15 disk-shaped specimens $(10 \times 1 \mathrm{~mm})$ were fabricated. Three shades of A1, A2 and A3.5 of porcelain (IPS e.MaxCeram, IvoclarVivadent, USA) were used for layering the specimens. Five specimens from each type of $\mathrm{Zr}$ were layered with same shade of ceramic. Color measurements were recorderd by a spectrophotometer Color-Eye ${ }^{\circledR} 7000 \mathrm{~A}$ (X-Rite, Grand Rapids, MI). Mean values of $\mathrm{L}, \mathrm{a}, \mathrm{b}$ color coordinates and $\Delta \mathrm{E}$ were recorded and comparisons were made.

Results: Differences in the $\Delta \mathrm{E}$ were recorded for the same porcelain shade with different $\mathrm{Zr}$ substructures and affected the color of the specimens ( $p<0.01$, ANOVA). The maximum difference between the $\Delta E$ values for the $A 1, A 2$ and $A 3.5$ shades with three types of $\mathrm{Zr}$ substructures was found to be $1.59,1.69$ and 1.45 respectively. Multiple comparisons of the $\Delta \mathrm{E}$ with PostHoc Tukey test revealed a statistically significant difference $(p<0.05)$ between the three types of $Z r$, except between Type $2 \mathrm{Zr}$ and Type $3 \mathrm{Zr}$ for the Shade A1. The mean values of $L, a, b$ and $\Delta E$ for the Prettau ${ }^{\circledR}$ Zirconia substructure were found to be the least among the three types.

Conclusions: The brand of $\mathrm{Zr}$ used influences the final color of the all ceramic $\mathrm{Zr}$ based restorations and this has clinical significance.

Keywords: Zirconia color, Zirconia shade, Zirconia, Ceramic shade, Zirconia substructure.

How to cite this article: Habib SR, AI Shiddi IF. Comparison of Shade of Ceramic with Three Different Zirconia Substructures using Spectrophotometer. J Contemp Dent Pract 2015;16(2): 135-140.

\section{Source of support: Nil}

Conflict of interest: None

1,2Department of Prosthodontics, College of Dentistry, King Saud University, Riyadh, Saudi Arabia

Corresponding Author: Syed Rashid Habib, Assistant Professor, Department of Prosthetic Dental Sciences College of Dentistry, King Saud University, Po Box-60169 King Abdullah Road, Riyadh 11545, Saudi Arabia, Phone: 0096614677441, e-mail: rashidhabib@hotmail.com

\section{INTRODUCTION}

One of the most challenging aspects of restorative dentistry is to achieve a natural looking restoration and the color matching of the restoration with the existing teeth is a difficult task. The difficulty of achieving good esthetics with metal ceramic crowns which is widely used over the last few decades has resulted in the increased use of all ceramic crowns. Ceramics are, however, brittle materials and cannot withstand deformation of $>0.1 \%$ without fracturing. To overcome this issue, high strength ceramic copings based on Zirconia (Zr) have been introduced. ${ }^{1-4}$

The use of $Z r$ has increased tremendously during the last few years which is due to its peculiar mechanical, optical, physical properties and its biocompatibility. ${ }^{5-7}$ Although the properties of $\mathrm{Zr}$ are promising, the tooth restoration unit forms a laminate system which consists of veneering ceramic, the coping material, the luting cement and the abutment tooth. All of these units may influence the ability of $\mathrm{Zr}$ based restorations to match the color with the adjacent natural teeth. ${ }^{8-16} \mathrm{Zr}$ substructures (copings) manufactured by different companies mostly are yttria-stabilized tetragonal Zr polycrystals (Y-TZP) with comparable compositions and may have slightly different microstructures. ${ }^{17}$ Because of this slight variation in the microstructure which results in light scattering they could have different degree of opacities. From an esthetic viewpoint a ceramic material should allow light transmission (be translucent) to simulate the optical characteristics of a natural tooth. ${ }^{3,5,10,11}$

Kelly et a ${ }^{3}$ demonstrated that core translucency was one of the primary factors in controlling esthetics. Only few data is available on the translucency of different $\mathrm{Zr}$ substructures. Heffernan et a $1^{10,11}$ reported the $\mathrm{Zr}$ to be a completely opaque material and it was later confirmed by Chen et al. ${ }^{12}$ In a study by Baldissara et $\mathrm{al}_{1}{ }^{18}$ light transmission through $\mathrm{Zr}$ was significantly lower than through lithium disilicate glass ceramics. The authors also reported different translucency values for different $\mathrm{Zr}$ materials. The current literature shows that $\mathrm{Zr}$ should be considered as low translucent to semi translucent core material. ${ }^{18,19} \mathrm{As}$ reported by Conrad et $\mathrm{al}^{20}$ it should be taken into consideration that the translucency measurements for $\mathrm{Zr}$ cores are carried out on core material in the absence of veneering material and are not 
representative of usual clinical conditions in which the presence of veneering porcelain also influences the final color of the restoration. In a study by Choi et $\mathrm{al}_{1}^{13}$ it was reported that the degree of masking ability of $\mathrm{Zr}$ coping can be further modified with the veneering porcelain. Suputtamongkol et $\mathrm{al}^{21}$ studied the effect of the color of a background substructures on the overall color of $\mathrm{Zr}$ based all ceramic crowns. No significant differences were observed between the $\mathrm{Zr}$ crowns cemented either on a metal cast post and core or a prefabricated post and composite core in their study. However, Kumagai et $\mathrm{al}^{22}$ in a study reported that the translucency of a Zr based all ceramic crowns may influence its esthetic outcome when it is used on a discolored abutment tooth.

Studies regarding the color of $\mathrm{Zr}$ based restorations are mostly focused on translucency of different $\mathrm{Zr}$ materials with various thicknesses, effect of the luting cements and various fabrication procedures. ${ }^{15-23}$ Studies related to the effect of $\mathrm{Zr}$ copings on the final shade of $\mathrm{Zr}$ based all ceramic restorations are scarce and the subject requires to be more widely investigated. ${ }^{1}$ With the availability of various brands of $\mathrm{Zr}$ substructures in the market, it is possible that altering the substructure may alter the color of the final veneering ceramic. It is, therefore, important to investigate the effect of different brands of $\mathrm{Zr}$ substructures on the final color of the restoration with the same shade of veneering ceramic. The aim of this in vitro study, therefore, was to evaluate and compare the effect of three brands of $\mathrm{Zr}$ substructures manufactured by different manufacturers on the resulting color of ceramic with the use of a spectrophotometer. The null hypothesis was that there would be no differences in the CIELAB color coordinates and $\triangle \mathrm{E}$ of a 1-mm-thick layer of ceramic fired on different $\mathrm{Zr}$ substructures.

\section{MATERIALS AND METHODS}

Three commercial $\mathrm{Zr}$ core materials were tested in this study: Cercon, Dentsply, Germany, InCoris ZI, Sirona, Germany and Prettau ${ }^{\circledR}$ Zirconia, ZirKonZahn, Italy. For each system, 15 disk-shaped specimens were designed and fabricated (10 $\mathrm{mm}$ diameter and $1 \mathrm{~mm}$ thickness). A power calculation was run on results from a previous study to determine the number of specimens $(\mathrm{SD}<0.40)$ needed to achieve an $80 \%$ power.

Two different techniques were used to fabricate the $\mathrm{Zr}$ disks. The Zr disks of Cercon and InCoris Zirconia blocks were prepared using water-cooled thin diamond disks in a low-speed straight headpiece (KaVo Dental). The specimens were rinsed to remove residue, and dried prior to sintering procedure. For the ZirKonZahn, the disks were prepared using a computer-aided milling process after scanning and digitizing a metal disk analog. The total number of the specimens was 45 . Each of the specimens was examined and measured twice in three different locations with a digital caliper (Mitutoyo Co, Kawasaki, Japan) to verify the shape, size and thickness.

Sintering procedure of all specimens were completed using a high-temperature furnace according to manufacturer instructions of each material (Sintramat furnace, Ivoclar Vivadent) resulting in approximately $20 \%$ shrinkage. The Zirconium disks were placed in the furnace and sintered at $1500^{\circ} \mathrm{C}$ for 7 hours. The shape and thickness of the specimens were adjusted after sintering with a cylindrical diamond flat-end bur (Dentsply Ltd, York, PA) and finishing disk (Indenco, Coirona, CA), to the final required shape and thickness. For the standardization, a digital caliper (Mitutoyo Co, Kawasaki, Japan) with an accuracy of $0.05 \mathrm{~mm}$ was used twice to measure the thickness in five different areas of each specimen and adjustments made if required. All specimens were ultrasonically cleaned in distilled water for 10 minutes and dried to be free of dirt and grease.

The specimens were divided into three groups of 15 samples with five specimens from each type of the $\mathrm{Zr}$ material. The $\mathrm{Zr}$ types were coded as type 1 Prettau ${ }^{\circledR}$ Zirconia (ZirKonZahn, Italy), type 2 Cercon (Dentsply, Germany) and type 3 InCoris ZI (Sirona, Germany). Three different shades of A1, A2 and A3.5 of IPS E.Max Ceram, low-fusing nano-flourapatite dentine porcelain (Ivoclar Vivadent, Schaan, Liechtenstein) were used for layering the specimens. Each of the group was layered with the same shade of ceramic to investigate the effect of the different types of $\mathrm{Zr}$ substructure on the shade of the ceramic. The veneering process began with a wash firing. Dentin porcelain powder was mixed with all round buildup liquid. A thin layer was applied on the entire surface of ZirLiner. The dentin porcelain slurry was condensed with vibration, and excess moisture was removed with paper tissue to minimize porosity. Group specimens were fired together in the sintering furnace (Multimat Touch \& press; Dentsply Ltd, York, PA) at $750^{\circ} \mathrm{C}$ for 1 minute. The addition of porcelain and a second dentine firing cycle was carried out to compensate for peripheral shrinkage of the initial veneering porcelain. Finally, the disks were ground and polished on the veneer side to the designated thickness of $1.0 \mathrm{~mm}$. The specimen's thickness was measured twice by a digital caliper (Mitutoyo Co, Kawasaki, Japan) with an accuracy of $0.05 \mathrm{~mm}$ in five different areas and adjustments made if required.

Glazing cycle was not performed. The porcelain surface was polished using three types of sand paper disks; s320-, 600- and 1200-grit sand paper disks in order to obtain a similar finishing surface in all the specimens. 
Specimens were then cleaned ultrasonically with distilled water for 5 minutes.

Color measurements were made by a laboratory spectrophotometer, Color-Eye ${ }^{\circledR}$ 7000A (X-Rite, Grand Rapids, $\mathrm{MI})$. The machine was designed to hold the sample in front of $10 \mathrm{~mm} \times 3 \mathrm{~mm}$ screen. Measurement procedure started by calibration of the machine and then measuring the color of three A1, A2 and A3.5 shade tabs (used for calculating $\Delta \mathrm{E}$ ) for the same porcelain system (IPS e.max Ceram shade guide) used with the Zr specimens. Three measurements were recorded for each shade tab and for each specimen, and the average was used for statistical analysis.

Table 1: Descriptive statistics of $\mathrm{L}, \mathrm{a}, \mathrm{b}$ and $\Delta \mathrm{E}$ values for different ceramic-zirconia combinations ( $n=5 /$ group)

\begin{tabular}{llllll}
\hline \multirow{2}{*}{$\begin{array}{l}\text { Ceramic } \\
\text { shade }\end{array}$} & Zirconia & \multicolumn{4}{c}{ Mean values } \\
\cline { 3 - 6 } substructure & $L$ & $a$ & $b$ & $\Delta E$ \\
\hline \multirow{2}{*}{ A1 } & Prettau® & 134.81 & -1.93 & 7.05 & 12.37 \\
& Cercon & 139.05 & -1.89 & 12.07 & 13.11 \\
& InCoris ZI & 135.41 & 1.15 & 19.12 & 13.44 \\
A2 & Prettau® & 129.46 & -1.20 & 9.70 & 12.00 \\
& Cercon & 131.34 & 1.22 & 20.20 & 13.17 \\
& InCoris ZI & 133.12 & 3.13 & 23.43 & 13.69 \\
A3.5 & Prettau® & 129.25 & -0.84 & 14.36 & 12.02 \\
& Cercon & 128.46 & 2.48 & 23.86 & 12.98 \\
& InCoris ZI & 129.65 & 3.94 & 27.70 & 13.47 \\
\hline
\end{tabular}

L: Degree of lightness; a: Degree of redness/greenness; $b$ : Value is degree of yellowness/blueness, $\Delta \mathrm{E}$ : Color differences between the shade tab and the samples

\section{Statistical Analysis}

Data were analyzed using SPSS V18.0.1 software package (SPSS, Inc., Chicago, IL, USA). The descriptive statistics included the mean values of $\mathrm{L}, \mathrm{a}, \mathrm{b}$ color coordinates and recording of $\Delta \mathrm{E}$ for each specimen of the three groups and comparison of these latter means (95\% CIs) across all three independent groups using one-way ANOVA and Tukey's post hoc test. The probability for statistical significance was set at $\alpha<0.05$.

\section{RESULTS}

The descriptive statistics of the spectrophotometric readings for same type of ceramic shade of A1, A2 and A3.5 with different types of $\mathrm{Zr}$ substructures are presented in Table 1. The Table describes the mean values for $L, a, b$ color coordinates and $\Delta \mathrm{E}$ for each of the Ceramic-Zirconia combination.

The mean values of $\mathrm{L}, \mathrm{a}, \mathrm{b}$ and $\Delta \mathrm{E}$ for the $\mathrm{Zr}$ (Prettau ${ }^{\circledR}$ Zirconia) substructure with ceramic layers of different shades A1, A2 and A3.5 were found to be the least and for the $\mathrm{Zr}$ (InCoris ZI) substructure were found to be the highest (Table 1). The maximum difference between the $\Delta \mathrm{E}$ values for the A1, A2 and A3.5 shades ceramic with three types of Zr substructures was found to be 1.59, 1.69 and 1.45 respectively.

Tables 2, 3 and 4 show the comparison of mean values of $\Delta \mathrm{E}$ for the three types of $\mathrm{Zr}$ substructures with different ceramic shades of A1, A2 and A3.5 showed a statistically significant difference $p<0.05$ with one-way analysis of variance.

Table 2: Comparison of $\Delta E$ values for combination of $A 1$ ceramic with different zirconia substructures $(n=5 / g r o u p)$

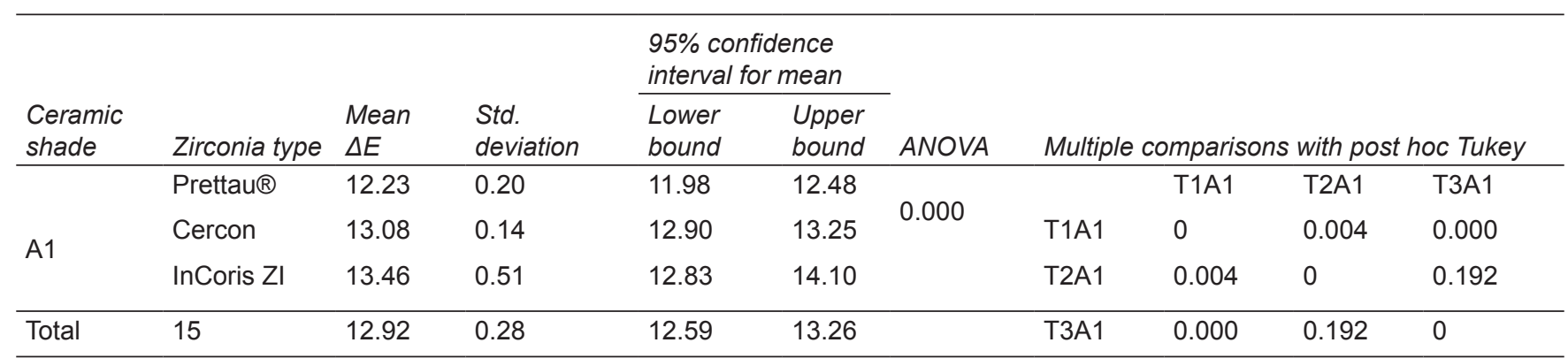

T1A1: Prettau ${ }^{\circledR}$ Zirconia with A1 shade ceramic; T2A1: Cercon zirconia with A1 shade ceramic; T3A1: InCoris ZI with A1 shade ceramic

Table 3: Comparison of $\Delta E$ values for combination of $A 2$ ceramic with different zirconia substructures $(n=5 /$ group $)$

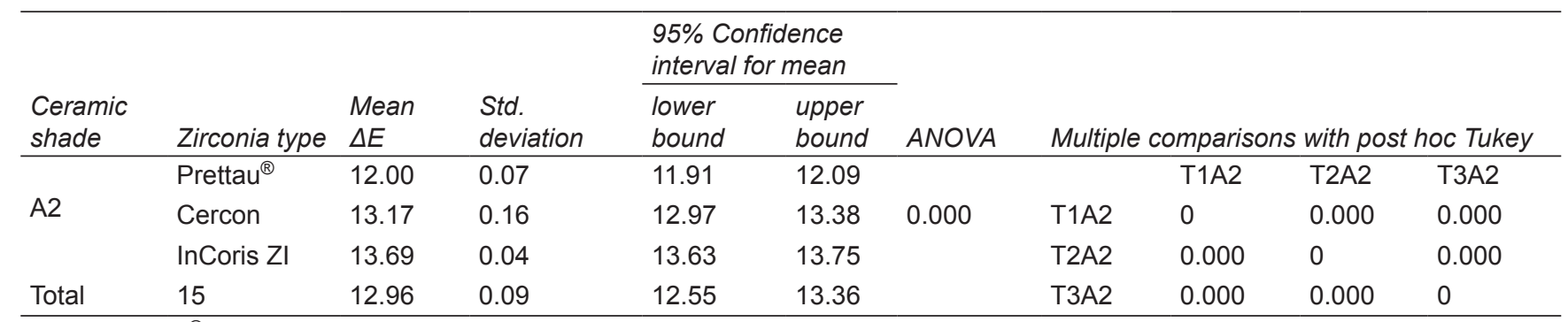

T1A2: Prettau $^{\circledR}$ Zirconia with A1 shade ceramic; T2A2: Cercon zirconia with A1 shade ceramic, T3A2: InCoris ZI with A1 shade ceramic 
Table 4: Comparison of $\Delta E$ values for combination of A3.5 ceramic with different Zirconia substructures $(n=5 / g r o u p)$

\begin{tabular}{|c|c|c|c|c|c|c|c|c|c|c|}
\hline \multirow[b]{2}{*}{$\begin{array}{l}\text { Ceramic } \\
\text { shade }\end{array}$} & \multirow[b]{2}{*}{ Zirconia type } & \multirow[b]{2}{*}{$\begin{array}{l}\text { Mean } \\
\Delta E\end{array}$} & \multirow[b]{2}{*}{$\begin{array}{l}\text { Std. } \\
\text { deviation }\end{array}$} & \multicolumn{2}{|c|}{$\begin{array}{l}95 \% \text { confidence } \\
\text { interval for mean }\end{array}$} & \multirow[b]{2}{*}{ ANOVA } & \multirow{2}{*}{\multicolumn{4}{|c|}{ Multiple comparisons with post hoc Tukey }} \\
\hline & & & & $\begin{array}{l}\text { Lower } \\
\text { bound }\end{array}$ & $\begin{array}{l}\text { Upper } \\
\text { bound }\end{array}$ & & & & & \\
\hline \multirow{3}{*}{ A3.5 } & Prettau $^{\circledR}$ & 12.02 & 0.08 & 11.91 & 12.13 & \multirow{4}{*}{0.000} & & T1A3.5 & T2A3.5 & T3A3.5 \\
\hline & Cercon & 12.98 & 0.12 & 12.83 & 13.13 & & T1A3.5 & 0 & 0.000 & 0.000 \\
\hline & InCoris ZI & 13.47 & 0.16 & 13.26 & 13.68 & & T2A3.5 & 0.000 & 0 & 0.000 \\
\hline Total & 15 & 12.82 & 0.12 & 12.47 & 13.17 & & Т3А 3.5 & 0.000 & 0.000 & 0 \\
\hline
\end{tabular}

T1A 3.5: Prettau $^{\circledR}$ Zirconia with A1 shade ceramic; T2A3.5: Cercon Zirconia with A1 shade ceramic; T3A3.5: In Coris ZI with A1 shade ceramic; ANOVA: Analysis of variance

Multiple comparisons of the three types of Zr with different ceramic shades with post hoc Tukey test revealed a statistically nonsignificant difference between the type 2 $\mathrm{Zr}$ and type $3 \mathrm{Zr}$ for the shade A1. All the rest of the comparisons revealed a statistically significant difference between the three types of the $\mathrm{Zr}$ substructures. The results of the Tukey's multiple comparison tests are listed in Tables 2, 3 and 4 .

\section{DISCUSSION}

For the restorations in the esthetic zone, all ceramic crowns are popular and widely used. $\mathrm{Zr}$ is currently choice of substructure used for all ceramic crowns, if high flexural strength or masking a heavily discolored tooth is desired. ${ }^{1,4,5}$ However, the color of the Zr substructure may influence the final shade of the veneering ceramic because of the availability of a number of $\mathrm{Zr}$ brands in the market. ${ }^{20-22}$ The selection of the brand of $\mathrm{Zr}$ substructure for a particular case is therefore a concern for the dentist. ${ }^{3}$ Samples of three brands of $\mathrm{Zr}$ substructures with same shade of veneering ceramics under standardized conditions were prepared and tested in the current study. To the authors knowledge no such study has been reported in the literature.

The results of this study supports rejection of the null hypothesis, as significant differences in CIELAB color coordinates $\left(L^{*}, a^{*}, b^{*}\right)$ and $\Delta E$ values of ceramic fired on different types of $\mathrm{Zr}$ substructures were noted. The CIELab* system was developed in 1976 and 1978 and it was possible to express color by numbers and calculate the differences between two colors in a way that corresponded to visual perception. In this system, which is regarded as the benchmark for scientific purposes, color is expressed by three coordinates: $\mathrm{L}^{*}$ value is the degree of lightness of an object, $\mathrm{a}^{*}$ value is the degree of redness/ greenness, and $b^{*}$ value is the degree of yellowness/blueness. In the CIELab* system a formula is used to calculate color differences: ${ }^{1,15,21,22}$

$$
\Delta \mathrm{E}_{\mathrm{ab}}=\left[\left(\mathrm{L}_{1}-\mathrm{L}_{2}\right)^{2}+\left(\mathrm{a}_{1}-\mathrm{a}_{2}\right)^{2}+\left(\mathrm{b}_{1}-\mathrm{b}_{2}\right)^{2}\right]^{1 / 2}
$$

This ' $\Delta \mathrm{E}^{\prime}$ value became pivotal in color science, for both industry and dentistry. Since spectrophotometers can detect small differences in color at a level that is not appreciable by the human eye, an important issue of color science in dentistry is to establish a reference value for the evaluation of study results in terms of $\Delta \mathrm{E}$. In other words, if in a study a certain difference in terms of $\Delta \mathrm{E}$ has been measured, it is important to understand whether this difference can be perceived by the human eye and, if so, whether this difference can be considered clinically relevant. $\Delta \mathrm{E}$ values of less than 1 unit were regarded as not appreciable by the human eye; $\Delta \mathrm{E}$ values greater than 1 and less than 3.3 units were considered appreciable by skilled operators, but clinically acceptable; $\Delta \mathrm{E}$ values greater than 3.3 were considered perceivable by untrained observers (eg patients), and for that reason were regarded as not acceptable. ${ }^{1,24-27}$ The results of the current study revealed a maximum difference between the $\Delta \mathrm{E}$ values for the A1, A2 and A3.5 shades ceramic with three types of $\mathrm{Zr}$ substructures was found to be 1.59, 1.69 and 1.45 respectively. Although, the comparison between the $\Delta \mathrm{E}$ of the three types of $\mathrm{Zr}$ substructures with same ceramic shade revealed a statistically significant difference $p<0.05$, the clinical value of these results are unclear because the maximum difference in the $\Delta \mathrm{E}$ values observed in the current study $(1.59,1.69$ and 1.45$)$ are close to 1 and therefore, not appreciable by a human eye.

Studies have shown that the shade of the core material and the luting cements has little effect on the final color of the ceramic restorations. This also depends on the thickness of the porcelain used. If the thickness is more than $1.5 \mathrm{~mm}$, its effect will be negligible. A thickness of $1 \mathrm{~mm}$ ceramics or less will have the effect of the shade of the core or cement on the final color of the ceramic restoration. This effect is because of the translucency of the all ceramic crowns. ${ }^{26-28} \mathrm{~A}$ similar conclusion can be drawn for the effect of the $\mathrm{Zr}$ substructures on the overall shade of the $\mathrm{Zr}$ based restorations with ceramic thickness of $1 \mathrm{~mm}$. This was tested in the current study and a statistically significant difference was observed between the $\Delta \mathrm{E}$ of the three types of the $\mathrm{Zr}$ substructures. However, the 
perceptible color difference is not clear because of the difference of $\Delta \mathrm{E}$ between the three types close to one.

There are some limitations of the study. $1 \mathrm{~mm}$ thick Zr substructure specimens were used. However, the translucency of the Zr may vary with its thickness. In the clinical situations a Zr substructure as thin as $0.3 \mathrm{~mm}$ can be used. ${ }^{22,28}$ This variation in thickness of the substructure can have influence on the final color of the restoration. Each specimen was prepared by same technician and verified for thickness of the $\mathrm{Zr}$ and ceramic layer applied. But the chances of human error during the sample preparation cannot be ignored. The translucency value for the different $\mathrm{Zr}$ materials varies and can be influenced by the luting cement and the core material. ${ }^{26,28}$ In the current study, spectrophotometric readings were recorded without the use of the luting cement and core material which can result in variation of the readings. Oral condition is very complex and it is almost impossible to mimic the actual clinical situation with this in vitro study. So the interpretation of the current results should be made with caution.

There are a number of $\mathrm{Zr}$ materials available in the market manufactured by different companies. However, studies about Zr based all ceramic crowns are limited. The physical and optical properties of these materials vary and the clinicians should keep this in mind while selecting a Zr based all ceramic crowns for their patients. Further studies in this regard are recommended to draw more relevant conclusions which can help the clinicians while choosing the materials for their patients.

\section{CONCLUSION}

Within the limitations of the study it can be concluded that; The final color of the all ceramic crowns with $\mathrm{Zr}$ substructure is influenced by the type of $\mathrm{Zr}$ used. Human eye may not detect the differences of the final shade. However, thickness of the porcelain layer and $\mathrm{Zr}$ substructure may affect the ability to detect the differences of the shade.

\section{ACKNOWLEDGMENT}

The authors are thankful to Mr Roseller Buenafe for his help in the preparation of the samples.

\section{REFERENCES}

1. Vichi A, Louca C, Corciolani G, Ferrari M. Color related to ceramic and zirconia restorations: a review. Dent Mater 2011 Jan;27(1):97-108.

2. Raigrodski A. Contemporary materials and technologies for all ceramic fixed partial dentures: a review of the literature. J Prosthet Dent 2004;92:557-562.
3. Kelly JR, Nishimura I, Campbell SD. Ceramics in dentistry: historical roots and current perspectives. J Prosthet Dent 1996;75:18-32.

4. Von Steyern PV, Ebbesson S, Holmgren J, Haag P, Nilner $K$. Fracture strength of two oxide ceramic crown systems after cyclic pre-loading and thermo cycling. J Oral Rehab 2006;33:682-689.

5. Chu FC, Chow TW, Chai J. Contrast ratios and masking ability of three types of ceramic veneers. J Prosthet Dent 2007;98:359-364.

6. Vichi A, Ferrari M, Davidson CL. Influence of ceramic and cement thickness on the masking of various types of opaque posts. J Prosthet Dent 2000;83:412-417.

7. Luthardt RG, Holzhuter M, Sankuhl O, Herold V, Schnapp JD, Kuhlisch E et al. Reliability and properties of ground Y-TZP-zirconia ceramics. J Dent Res 2002;81:487-491.

8. Ozkurt Z, Kazazoglu E. Clinical success of zirconia in dental applications. J Prosthodont 2010;19:64-68.

9. Chistensen GJ. Choosing an all ceramic restorative material: porcelain fused to metal or zirconia based? J Am Dent Assoc 2007;138:662-665.

10. Heffernan MJ, Aquilino SA, Diaz-Arnold AM, Haselton DR, Stanford CM, Vargas MA. Relative translucency of six allceramic systems. Part I: core materials. J Prosthet Dent 2002 Jul;88(1):4-9.

11. Heffernan MJ, Aquilino SA, Diaz-Arnold AM, Haselton DR, Stanford CM, Vargas MA. Relative translucency of six allceramic systems. Part II: core and veneer materials. J Prosthet Dent 2002 Jul;88(1):10-15.

12. Chen YM, Smales RJ, Yip KH, Sung WJ. Translucency and biaxial flexural strength of four ceramic core materials. Dent Mater 2008 Nov;24(11):1506-1511.

13. Choi Y, Razzooq ME. Masking ability of zirconia with and without veneering porcelain. J Prosthodont 2013;22(2):98-104.

14. Antonson SA, Anusavice KJ. Contrast ratio of veneering and core ceramics as a function of thickness. Int J Prosthodont 2001;14:316-20.

15. Lee YK, Cha HS, Ahn JS. Layered color of all ceramic core and veneers. J Prosthet Dent 2007;97:279-286.

16. Aboushelib MN, Dozic A, Liem JK. Influence of framework color and layering technique on the final color of zirconia veneered restorations. Quintessence Int 2010;41:84-89.

17. Ho-Jung S, Woong-Chul K, Sang-Ho J, Young-Su K, SungWon J, Jin-Soo A. Influence of dentin porcelain thickness on layered all-ceramic restoration color. J Dent 2010;38(2):71-77.

18. Baldissara P, Llukacej A, Ciocca L, Valandro FL, Scotti R. Translucency of zirconia copings made with different CAD/ CAM systems. J Prosthet Dent 2010;104:6-12.

19. Guazzato M, Albakry M, Ringer SP, Swain MV. Strength, fracture toughness and microstructure of a selection of allceramic materials. Part II. Zirconia-based dental ceramics. Dent Mater 2004 Jun;20(5):449-456.

20. Conrad HJ, Seong WJ, Pesun IJ. Current ceramic materials and systems with clinical recommendations: a systematic review. J Prosthet Dent 2007;98:389-404.

21. Suputtamongkol K, Tulapornchai C, Mamani J, Kamchatphai W, Thongpun N. Effect of the shades of background substructures on the overall color of Zirconia-based all ceramic crowns. J Adv Prosthodont 2013;5:319-325.

22. Kumagai N, Hirayama H, Finkelman MD, Nagai SI. The effect of translucency of Y-TZP based all ceramic crowns fabricated with different substructure designs. J Dent 2013;41(3):87-92. 
23. Luo XP, Zhang L. Effect of veneering techniques on color and translucency of Y-TZP. J Prosthodont 2010 Aug;19(6):465-470.

24. Inokoshi S, Burrow MF, Kataumi M, Yamada T, Takatsu T. Opacity and color changes of tooth-colored restorative materials. Oper Dent 1996;21:73-80.

25. Nagai SI, Yoshida A, Sakai M, Kristiansen J, Da Silva JD. Clinical evaluation of perceptibility of color differences between natural teeth and all ceramic crowns. J Dent 2009;37: 57-63.
26. Li Q, Yu H, Wang YN. Spectrophotometric evaluation of the optical influence of core build up composites on all ceramic materials. Dental Materials 2009;25:158-165.

27. Jarad FD, Moss BW, Youngson CC, Russell MD. The effect of porcelain thickness on color and the ability of a shade guide to prescribe chroma. Dental Materials 2007;23:456-460.

28. Chang J, Da Silva, Sakai M, Kristiansen J, Nagai SI. The optical effect of composite luting cement on all ceramic crowns. J Dent 2009;37:937-943. 